\title{
The Impact of Biogas Conversion Technology for Economic Development: A Case Study in Kilimanjaro Region
}

\author{
L. L. N. Mkiramweni \\ Dar es Salaam Institute of Technology, P.O. Box 2958, Dar es Salaam, Tanzania \\ Correspondence should be addressed to L. L. N. Mkiramweni, lmkiramweni@yahoo.com
}

Received 7 February 2012; Accepted 29 February 2012

Academic Editor: C. J. Koroneos

Copyright ( $) 2012$ L. L. N. Mkiramweni. This is an open access article distributed under the Creative Commons Attribution License, which permits unrestricted use, distribution, and reproduction in any medium, provided the original work is properly cited.

In Tanzania the overall performance of the country's social and economic development requires the minimization of the existing energy challenges. Currently, about $80 \%$ of Tanzanians live in rural areas, and $90 \%$ percent of the populations have no access to grid electricity but rely on fuel wood and charcoal, causing annual deforestation rates of about 500,000 hectares. This problem can be minimised, especially where there is potential, like Kilimanjaro region. However, the level of development of biogas in the region is low and no reliable data to show this effect quantitatively. The author here, therefore, attempts to fill the gap. He realizes that up to 0.5 giga $\mathrm{m}^{3}$ of biogas could be produced daily, exceeding by far the 0.72 million $\mathrm{m}^{3}$ required for cooking in the region. It was further observed that the energy required for small economic activity in the region is about $3.0 \mathrm{MWh}$, about $0.1 \%$ of the total energy that can be generated from agrowaste materials. The application of biogas in Kilimanjaro region is therefore technically feasible, socially acceptable, and economically viable, so sensitisation should therefore be enhanced and research conducted.

\section{Introduction}

The energy challenges in Tanzania impart seriously on the overall performance of the country's social and economic indicators. The country relatively poor income, poor health, and education indicators can be greatly improved with the provision of modern energy service. The application of modern energy services in Tanzania is very low. For example, the national grid electrification is still very low and mainly covers the urban dwellers who are less than a fifth of the country population [1]. Increased availability of and electricity access for different economic activities can lead to better income resulting in poverty reduction. Furthermore, improving the added value of Tanzania products will require modern energy provision for manufacturing, processing, storage, and transportation. Availability of and electricity access for health facilities can lead to better health care. Modern educational facilities depend largely on the availability of modern energy services. At present, about $23 \%$ of the people in the country use electricity for lighting this cannot facilitate improved student performance. Specifically, the sources of energy being used by the majority of Tanzanians are either very ineffective and/or inefficient for realising the socioeconomic development. Currently, $80 \%$ of Tanzanians live in rural areas, and $90 \%$ of the energy requirements of these people are met by firewood and charcoal $[2,3]$.

At present firewood and charcoal account for about $60 \%$ and $35 \%$ of the total energy used for cooking in Tanzania, respectively [4]. The extensive use of firewood and charcoal as sources of energy is resulting in deforestation and hence degradation of the environment. Currently, the availability and cost of charcoal and firewood for fuel are major problems for most urban and rural residents, respectively. In Dar es Salaam charcoal accounts for about $83 \%$ of the total energy required for cooking, while in other urban areas firewood and charcoal account for about $34 \%$ and $57 \%$ as source of energy for cooking respectively [4]. Depending on firewood and charcoal as the major sources of energy has several disadvantages such as environmental degradation, health problems, unsuitability for economic activities, timeconsuming activity, and nonrenewable source. For environmental degradation in 1997 National Forestry Policy aimed 
to develop sustainable regimes for soil conservation and forest protection in order to prevent desertification and deforestation, preserve freshwater availability and biological diversity, and account for climate change in general. This will be possible if the society will have an alternative energy source which is reliable and affordable. Considering health problems, Banerjee [5] pointed out chronic diseases that are associated with the indoor combustion of biomassbased fuels, such as respiratory infections, ailments of the lungs bronchitis, asthma, lung cancer, and increased severity of coronary artery disease. These types of diseases can be minimized if not eliminated if people can use modern sources of energies. The daily task of firewood gathering, which can, in areas of scarcity, be the single most time consuming task of a woman's day, takes more than three hours in some areas [6]. Hazole and Harper [7] have reported cases in Mvomero district where average oneway distances to firewood collection sites exceed $5-7 \mathrm{~km}$. Dejene et al. [8] also indicated the same trend at Mrijo Chini village in Kondoa district, where farmers walk more than $10 \mathrm{~km}$, one way, to collect firewood. Minimising the dependence of firewood and charcoal can in one way or another save the time and energies of the people in rural areas. The introduction of tubular plastic biodigesters to some households in Turian Morogoro has cut down firewood by 60 to $70 \%$ to the respective household [9]. The recent survey conducted by the Tanzania Government to gauge the midterm implementation of National Strategy for Growth and Reduction of Poverty (NSGRP) cited the increased cost of firewood and charcoal to be the major current problem affecting people's livelihoods [4].

This needs to be considered. One option is to promote the use of biogas fuel, considering its potential and advantages over fuelwood and charcoal. Biogas provides a clean and easily controlled source of renewable energy and, when adequately applied, can significantly minimise the observed rate of deforestation in the country. Biogas has dual potential applications; it can either be used directly to replace firewood and charcoal and hence minimise the rate of deforestation or it can be converted to electricity using heat engine and solve electric energy challenges. The biogas conversion technology is expected to have positive impact in poverty alleviation and deforestation in the region. The users of biogas in the region can benefit more from it if it can be converted to electricity by using heat engine. The heat engine transforms the chemical energy of biogas into thermal energy to produce rotational energy, required by electricity-generating machines. There are two approaches that are being pursued for conversion of the chemical energy from biogas to electrical energy. In the first, the internal combustion (spark and compression ignition) engines are modified to use biogas as fuel. Most research on energy conversion with compression ignition engine (CIE) is on the use of dual fuel (diesel and biogas) while in spark ignition engine that uses gasoline biogas completely replaces gasoline after modification [10-13]. In the second, external combustion engines can be fabricated, for example, hot air engine that can use biogas as fuel. Such engines are relatively simple in designing, and production and they can hence be fabricated locally and are easier in operation and maintenance. They are also more flexible in terms of fuel consumption and are relatively quiet and with reduced exhaust emission. In order to take advantage of these positive attributes, it is critical to understand the characteristics of hot air engine better. Hot air engine performance has been simulated to suit electricity generation under rural setting where independent power provider is applicable. In order to maximise the benefits of biogas as an alternative source of fuel, more efforts need therefore to be directed to promote the technology in areas where there is adequate potential. Kilimanjaro region is one of the locations in Tanzania where potential for biogas production and use exists and is significant. The actual level of biogas application in the region, however, is currently still very low, and reliable data to show this effect quantitatively have not yet been obtained.

A study has therefore been conducted by the author of this paper to quantify the existing potential for biogas conversion technology in economic development in Kilimanjaro region, and the results are herein reported. In doing so, the challenges that constrain realisation of biogas as a reliable energy source for the majority of the population in the region have been established and the required interventions proposed. It is anticipated that the information will contribute towards the promotion of biogas production and utilisation in the region, hence maximising the positive impact of this renewable energy to the society.

\section{Materials and Method}

An extensive literature review was done to estimate the energy requirements of Kilimanjaro region. This was enhanced with a baseline study conducted in the locality for gathering primary and some of the secondary data. This was intended to qualify and quantify the conditions that support or could support biogas production and utilisation in the region. A structured questionnaire was administered for that purpose and complimented with physical interviews covering 179 respondents. The respondents included producers and owners of biogas plants in the region, known users and potential users of biogas as well as promoters of the biogas technology. Respondents were identified through the review of various documents $[14,15]$, and subsequent tracing, and were also complemented with information from the Centre for Agricultural Mechanisation and Rural Technology, who are widely considered to be pioneers of the biogas technology in Tanzania.

The questionnaire and interviews were administered with a view to assessing the available inputs for biogas production in the region and establishing corresponding potentials. The study instruments also focused to register the types and sizes of biogas technology currently being used in the region, areas of application, and corresponding challenges the users are facing. The areas of biogas applications which this study targeted to assess included direct cooking, direct lighting, generation of electricity for households (radio, lighting, cooking, ironing, refrigeration, and the like), generation of electricity for-small scale industrial activities 
(e.g., lumbering, grain milling, water pumping, welding and fabrication, carpentry and joinery, etc.), and the combinations thereof. The extent to which the biogas technology has been disseminated was also gauged together with the level of its acceptance in the region. In all cases, the respondents gave the names of appliances they own, engine model, and the extent of use, as the case may be.

2.1. Situation Analysis. The part describes the material and method used to estimate the potential and extent of biogas production and utilization. Considering the size of the biogas plant of $24 \mathrm{~m}^{3}$ the daily gas production is about 6000 litres $\left(6 \mathrm{~m}^{3}\right)$, while gas produced per hour is $250 \mathrm{~L} / \mathrm{h}$ $\left(0.25 \mathrm{~m}^{3} / \mathrm{h}\right)$. The biogas production from the biogas plant is divided into two applications. The first application is where biogas is used directly for cooking and lighting while in the second application the chemical energy of biogas is converted to electric energy. Gas consumption from 0600 to $0700 \mathrm{hrs}=1 \mathrm{hr}$, from 1100 to $1400 \mathrm{hrs}=3 \mathrm{hrs}$, from 1400 to $1500 \mathrm{hrs}=1 \mathrm{hr}$, From 1900 to $2300 \mathrm{hrs}=4 \mathrm{hrs}$. Duration of gas production and consumption is 24 and 9 hours, respectively. For simplicity, uniform gas production is assumed. Hourly gas consumption is $667 \mathrm{~L} / \mathrm{h}\left(0.667 \mathrm{~m}^{3} / \mathrm{h}\right)$. Gas is also produced during consumption. For this reason, only the difference between consumption and production is relevant to the calculation. Gas demand $\mathrm{Dg}=667 \mathrm{~L} / \mathrm{h}-250 \mathrm{~L} / \mathrm{h}=$ $417 \mathrm{~L} / \mathrm{h}$. The necessary gas holder size during consumption is therefore $V_{g}(1)=417 \mathrm{~L} / \mathrm{h} \times 4 \mathrm{~h}=1676 \mathrm{~L}$. The longest interval between periods of consumption from 2300 to $0600 \mathrm{hrs}$ ( 7 hours). The necessary gasholder size is therefore; $V_{g}(2)=$ $250 \mathrm{~L} / \mathrm{h} \times 7 \mathrm{~h}=1750 \mathrm{~L}$. Engine was operated from 1400 to 1500 , and about $V_{g}(3)=2400 \mathrm{~L}$ of biogas was used. This is more than the gas collected during the night. Therefore, $V_{g}(3)$ is the relevant volume to determine the size of the gasholder. The necessary gas holder size during consumption is therefore; $V_{g}(1)=417 \mathrm{~L} / \mathrm{h} \times 4 \mathrm{~h}=1676 \mathrm{~L}$. the longest interval between periods of consumption from 2300 to 0600 hrs ( 7 hours). The necessary gasholder size is therefore; $V_{g}(2)=250 \mathrm{~L} / \mathrm{h} \times 7 \mathrm{~h}=1750 \mathrm{~L}$. Engine was operated from 1400 to 1500 and about $V_{g}(3)=2400 \mathrm{~L}$ of biogas was used. This is more than the gas collected during the night. Furthermore, the gas holder must be able to compensate for daily fluctuations in gas production. These fluctuations range from $75 \%$ to $125 \%$ of calculated gas production. Therefore, $V_{g}(3)$ is the relevant volume to determine the size of the gasholder. The maximum relevant gasholder size with the safety margin of $25 \%$, this gives gas holder size of, $V_{g}=$ $2400 \mathrm{~L} \times 1.25=3000 \mathrm{~L}$. The required gasholder capacity is thus $\mathrm{C}=3000 / 6000=50 \%$. A gasholder capacity of $50-60 \%$ is normally correct.

2.2. Characteristics Performance of Hot Air Engine. This part describes the materials and method used to acquire improved characteristics performance of hot air engine. The performance of hot air engine is largely dependent on the design and optimisation of the engine heat exchangers such as cooler, heater, and regenerator. The existence of numerous design parameters and their interrelationship, however, pose a significant problem towards the optimisation of heat exchangers performance. This calls for application of modern modeling techniques using simulation programs. In this study a Stirling thermodynamic design and analysis program known as SNAP (Stirling Numerical Analysis Program) was used for simulation. The program has built in graphic capabilities and user modifiable code, so new heat exchanger geometries can be added or new constructions modeled. The input part of the program accepts and controls all the input of the geometric parameters and operational parameters of the engine. The output part of the program produces the brake power, brake efficiency, and engine losses. It is fastrunning program to analyze the engine as a whole and display its performance. The program was validated using the actual values for geometrical and operational parameters of the engines. During simulation several assumptions were made for proper operation of the engine, and this constituted one of the major contributions of this study.

2.3. Assumptions for Simulating Optimum Engine. The following basic assumptions were used during simulating the hot air engine.

(i) The gas specific heats are constant.

(ii) The heat capacity of the wall is much greater than that of the gas, and therefore the wall temperature is taken as constant.

(iii) The velocity gradient normal to the cylinder sides is negligible.

(iv) The flow of the working gas is one-dimensional throughout the engine.

(v) Velocity, $u$. working gas temperature, $T_{g}$, and pressure. $P$, at a given location is uniform across a section perpendicular to the flow.

(vi) The Fourier modulus of the individual solid element is such that a temperature disturbance perpendicular to the fluid flow propagates instantaneously.

(vii) Volumetric porosity, $\S_{\mathrm{v}}$, free-flow area, $A_{\mathrm{ff}}$ (which depends on $\S_{\mathrm{v}}$ ) are uniform, as are physical properties of working gas and solid.

2.4. Optimisation of the Power Output and Efficiency. The simulation point of an optimization of a Stirling engine was generally somewhere between the two limits of the maximum efficiency and power. Geometrical and operational parameters of the engine were used during engine performance optimization. Different activities were performed to determine the optimal performance of the Stirling hot air engine. The optimal relation between power output and efficiency was derived by $\mathrm{Wu}$ et al. [16], considering the conservation of energy. The net power output $(P)$ was found by dividing the net work output $(W)$ by the cycle period $(\tau)$ :

$$
P=\frac{W}{\tau}=\frac{n R\left(T_{h}-T_{c}\right) \ln \lambda}{\tau} .
$$

The cycle period $(\tau)$ is the time for the individual process times, $\lambda$ is the compression ratio, and $T_{h}$ and $T_{c}$ are the heat 
source and heat sink temperature, respectively. Substituting the expressions for the cycle period time in (1) yields

$$
P=\frac{\alpha\left(1-N_{T}\right)}{\left\{\left[1+\mu\left(1-N_{T}\right)\right] /\left(T_{h}-T_{c}\right)+\left[N_{T}+\mu\left(1-N_{T}\right)\right] /\left(N_{T} T_{h}-T_{c}\right)+A\left(1-N_{T}\right)\right\}},
$$

where $N_{T}=T_{h} / T_{c}, A=\alpha\left(k_{1}+k_{2}\right) /\left[n c_{v}(k-1) \ln \lambda\right]$ and $\mu=x /[(k-1) \ln \lambda], \alpha$ is the heat conductance between the engine and the reservoirs, $k_{1}$ and $k_{2}$ are constant of the two regenerative processes, $x$ is imperfect regeneration coefficient, and $k$ is the ratio of specific heat. The thermal efficiency $(\eta)$ of the engine is

$$
\eta=\frac{W}{Q_{\text {in }}}=\frac{\left(1-N_{T}\right)}{\left[1+\mu\left(1-N_{T}\right)\right]} \text {. }
$$

Equation (3) gives the general relationship between power output and thermal efficiency of the Stirling engine. It also shows that the performance of heater and cooler temperature has impact in the power and efficiency of the engine.

\section{Assessment of Conditions for Biogas Production}

3.1. Geographical Conditions. Kilimanjaro is one of the twenty-six regions of Tanzania. Kilimanjaro region comprises of six districts, namely, Moshi rural, Hai, Rombo, Same, Moshi urban, and Mwanga, with total of about 1.38 million inhabitants and about 0.3 million households [17]. The Region is on the northern side of Tanzania, characterised by mountains, plateaus, and low lands, generally subjected to a warm, equatorial climate, considered very good conditions for biogas technology application. Due to the variation in the land profile of Kilimanjaro region, the production of biogas is also expected to vary. According to van Nes [18], biogas production per $\mathrm{kg}$ of cow dung is $0.02 \mathrm{~m}^{3}$ in the mountains, $0.03 \mathrm{~m}^{3}$ in the hills, and $0.04 \mathrm{~m}^{3}$ in the terrain, and it is $0.07 \mathrm{~m}^{3}$ per $\mathrm{kg}$ of night soil. Temperature is one of the important factors with mesophilic optimum reached at about $23-37^{\circ} \mathrm{C}$. Figure 1 shows the map of Kilimanjaro region and the numbers of households per districts. Moshi rural and Hai districts comprise about $48 \%$ of the total population of Kilimanjaro region.

3.2. Availability of Inputs for Biogas Production. The source for biogas production can be organic waste materials such as crop, animal, people, and industrial wastes. Crop and animal wastes are abundant in Kilimanjaro region, since its economy is essentially agricultural based. According to the National Sample Census [19], about 117,937 hectares of land in the region are under annual crop production. Agrowaste from this land could produce about 0.5 giga cubic meters of biogas. This is $43 \%$ of the total area of the region giving a clear indication of the existence of plenty of agrowastes. Figure 2 presents the potential of biogas from different sources such as livestock and night soil from people which are available in Kilimanjaro region. From these sources of biogas about $78 \%$ comes from cattle dung and from the night soil of the people. These sources of energy can just solve about 25\% of the energy required for cooking in the region. The remaining $75 \%$ of biogas energy can be produced from 114 ha of the agrowaste. Actually the agrowaste from 155 ha is sufficient to produce biogas enough for cooking in Kilimanjaro region which is less than one percent of the available hectares under annual crop production in the region. With the prevailing temperatures and the existing potential of agrowaste materials from the land under annual crop production, it is possible to produce up to 0.55 billion $\mathrm{m}^{3}$ of biogas per day.

Further, the region has a reasonable livestock population of about 3.0 million to include 0.5 million cattle, about 0.6 goats, 0.1 pigs, and 0.3 sheep [17]. The specific daily energy potentials of the available biogas sources from livestock and people in Kilimanjaro region are as shown in Figure 2. With the prevailing temperatures in the region, it is possible to produce up to $129,000 \mathrm{~m}^{3}$ of biogas daily $(0.77 \mathrm{GWh}$ of energy) from available cow dung alone. Furthermore, Figure 3 presents the percentage availability of inputs to biogas production from the livestock population and people in Kilimanjaro region. The livestock under consideration are cattle, goats, sheep, pigs, and chickens available in the region. Together with this it is possible to produce biogas from night soil of the people. From these sources it is possible to produce about 0.23 million cubic meter of biogas per day. Using these sources of energy for cooking it is possible to serve about 0.81 million kilogram of firewood. Also this energy can be used for cooking to about 97,000 households per day in the region.

It can be seen in Figure 3 that dung from cattle is the most available substrate (over 55\%), followed by other animals (goat, chicken, pig, and sheep) which contribute $25 \%$ in total, although their wastes can be treated and mixed with cow dung in the same digester for biogas production. Further, night soil from people (20\%) can also be connected directly to the digester without passing through the mixing chamber. This simplifies the whole process for biogas production since same digester can be utilised with various substrates. Figure 4 shows the amount of biogas that can be produced from night soil in each district. The total amount of biogas that can be produce from night soil is about $47,000 \mathrm{~m}^{3}$, most of it coming from three districts, namely, Moshi Rural, Hai, and Rombo as it is clear from the figure.

It is important to note that the Moshi Urban district has the additional advantage through its anaerobic treatment of industrial and municipal wastewaters, which can produce an additional $8,660 \mathrm{~m}^{3}$ of biogas per day. In totality, with 


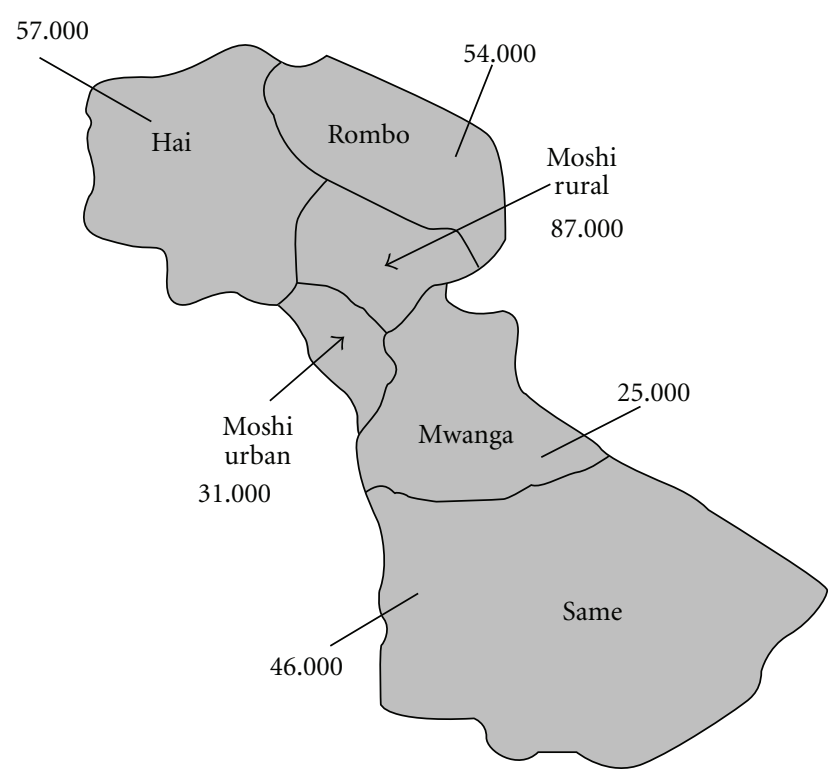

Figure 1: Numbers of households per districts in Kilimanjaro region.

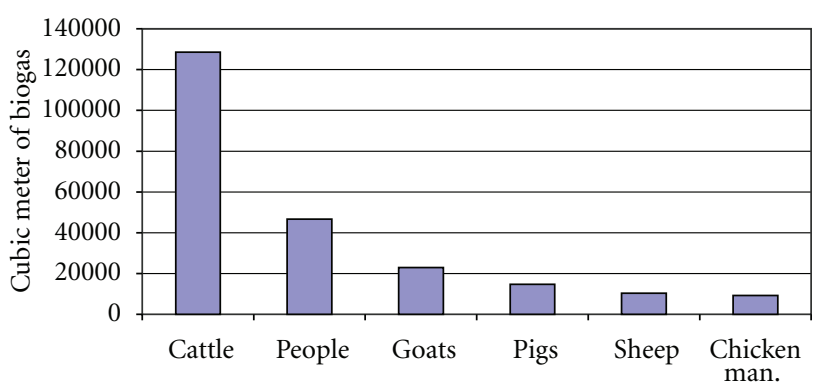

FIGURE 2: Biogas from livestock and night soil of the people.

the prevailing temperatures and the existing volume of agrowaste materials, animal dung, night soil, and wastewaters, it is possible to produce more than 0.5 billion $\mathrm{m}^{3}$ of biogas per day. From such level of biogas production, the slurry that will be available will also cause significant multiplier positive effects to the region. Specifically, about $32 \mathrm{~kg}$ of dung is used per day for producing $1 \mathrm{~m}^{3}$ of biogas. This entails that $11,680 \mathrm{~kg}$ of dung will be used annually, which will contain about $14 \mathrm{~kg}$ of nitrogen. In terms of fertilizer content, this is equivalent to $30.4 \mathrm{~kg}$ of urea fertiliser consisting of about $46 \%$ nitrogen. Practical experiments in Turiani, Mvomero district, for example, have already indicated significant increase in the yields when slurry was used in banana cultivation and gardening [20].

\section{Estimated Requirement of Energy for Cooking}

4.1. Energy Required for Cooking per District and Household. About $90 \%$ of the energy required for household activities in Kilimanjaro region is for cooking. Energy requirements

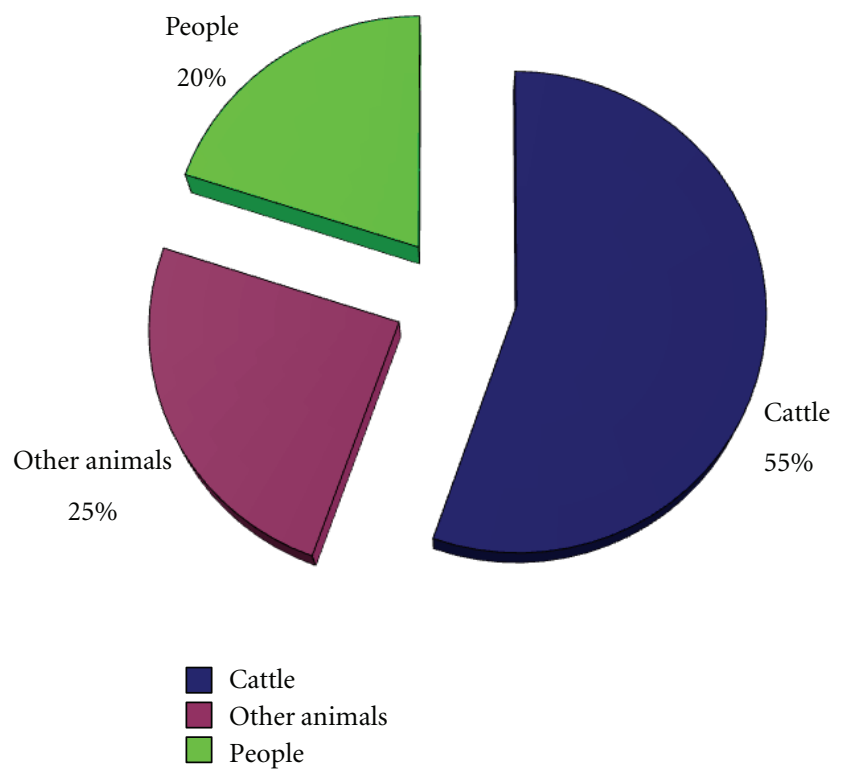

FIGURE 3: Percentage availability of inputs to biogas production from the livestock population and people.

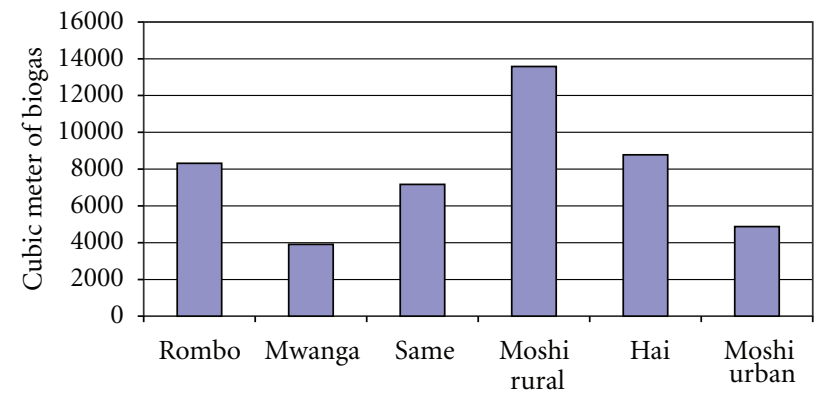

FIGURE 4: Biogas production potential from night soil in the districts.

for cooking depend on the number of family members within a household and type of food to be prepared. Table 1 indicates the respective number of households in the 6 districts of Kilimanjaro region and requirements of biogas for cooking per day, based on the average number of people. It can be seen that Kilimanjaro region with about 0.3 million households requires about 0.72 million cubic metres of biogas per day to support cooking of three meals in each household. It is important to note that about $29 \%$ of the total energy requirements come from Moshi Rural, being the most populous district in the region. When compared with the available potential for biogas production $\left(0.5\right.$ billion $\left.\mathrm{m}^{3}\right)$ in the region, the above total requirements of biogas for cooking $\left(0.72\right.$ million $\left.\mathrm{m}^{3}\right)$ can easily be met. This will still be the case even if only a fraction, say $42 \%$, of all the dung and agrowastes is collected. As such, if all the dung and agrowastes were collected, apart from using the resulting energy to support cooking, the surplus can be used for other purposes also. The other purposes may include lighting and conversion to mechanical power for 
TABLE 1: Biogas energy required for cooking per district.

\begin{tabular}{lccccccc}
\hline District & Moshi Rural & Hai & Rombo & Same & Moshi Urban & Mwanga & Regional total \\
\hline Number of household & 87,485 & 56,512 & 53,582 & 46,157 & 31,377 & 25,134 & 300,249 \\
\hline 1 Meal & 69,988 & $45,210.1$ & $42,865.9$ & $36,926.1$ & $25,101.9$ & $20,107.8$ & $240,199.8$ \\
2 Meals & 139,976 & $90,420.2$ & $85,731.8$ & $73,852.2$ & $50,203.8$ & $40,215.6$ & $480,399.7$ \\
3 Meals & 209,964 & $135,630.3$ & $128,597.7$ & $110,778.2$ & $75,305.7$ & $60,323.4$ & $720,599.5$ \\
\hline
\end{tabular}

water pumping, grinding, and plowing, or to electrical power and take advantage of all that electricity can offer.

\subsection{The Potential of Agrowaste for Cooking in Kilimanjaro} Region. Figure 5 shows the hectares required for producing enough biogas from agrowaste for cooking in each district. Moshi rural and Hai require about $47 \%$ of the total hectares required for cooking in Kilimanjaro region. Utilisation of cow dung in the region is possible to solve about $18 \%$ of the total energy required for cooking in the region. Agro waste from the region can be used to solve the problem of energy required for cooking. The region has the highest number of crop-growing households per squire kilometer. The biogas production from the agrowaste from the total land under crop production in Kilimanjaro region can range from 0.3 to 0.7 giga cubic meters per day while the biogas required for cooking in this region is about 0.72 million cubic meters per day.

\subsection{Energy from Agrowaste to Support Cooking in the Region.} Figure 6 shows how biogas from agrowaste can be used to support cooking in the region. Actually, if it is possible to utilize all the available night soil and all the manure from livestock, it is possible to supply a quarter of the required energy for cooking. But using agro waste from 114 ha which is about $0.1 \%$ of the total ha of the agro waste, it is possible to generate about 0.5 million cubic metres of biogas. This amount of biogas from the agro waste can be utilized with the available night soil and livestock dung to solve the problem of energy required for cooking in Kilimanjaro region.

\section{Level of Satisfaction of Biogas Users in Kilimanjaro}

Figure 7 shows the three levels of satisfaction from some of the biogas users in Kilimanjaro region. From this information it can be seen that about $53 \%$ of the respondents in this region are either satisfied or partially satisfied. Considering the importance of biogas as source of energy and a viable means for rescuing our environment it is very important to consider those who are not satisfied. Actually, from the research we have observed that most of the problems are technical and they can be solved using technical people.

\section{Percent of Household Having Electricity}

Figure 8 presents the percentage of household having electricity in each district in Kilimanjaro region. Moshi urban

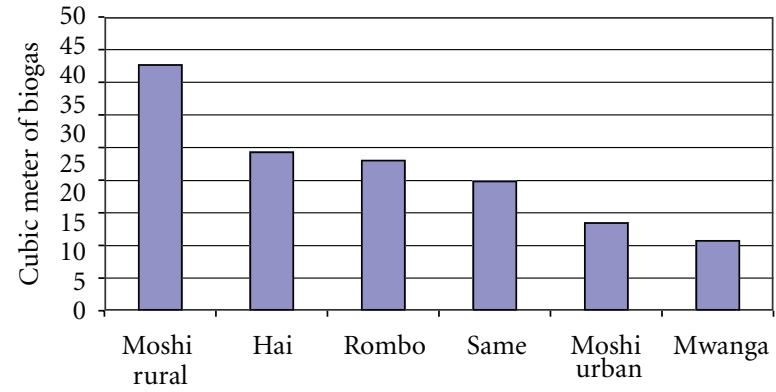

Figure 5: Hectares required for producing enough biogas for cooking in each district of Kilimanjaro region.

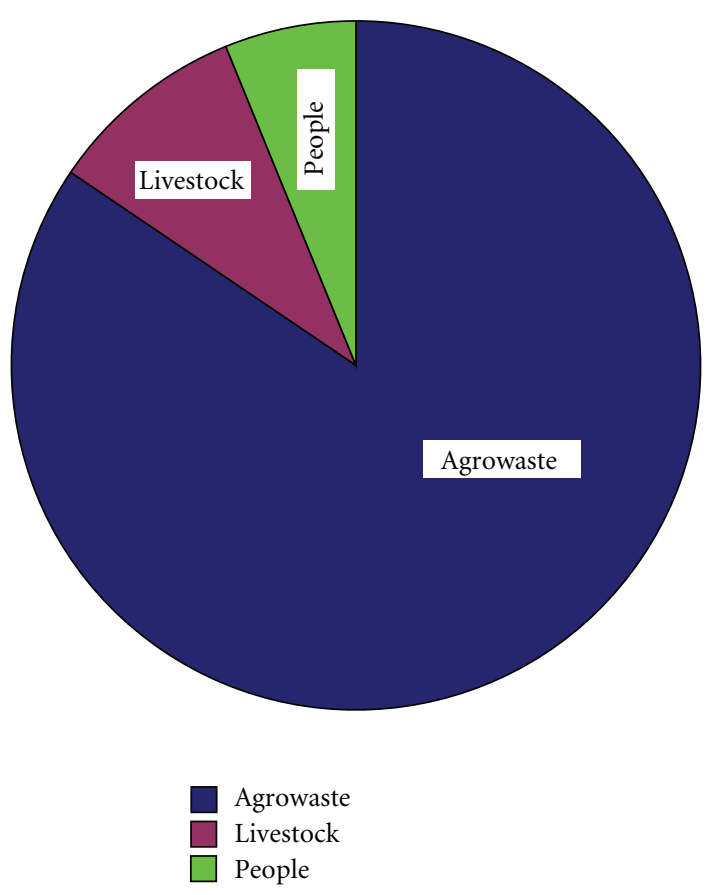

FIGURE 6: Total energy required for cooking in Kilimanjaro.

district has the highest percentage of about $46.6 \%$ of household with electricity followed by Mwanga district with about $22.1 \%$. On the other hand Rombo district has the lowest percentage of about $7.7 \%$ followed by Same with $9.8 \%$. From this data it is shown that about $19 \%$ is the percentage of household with electricity per region which is very low. 


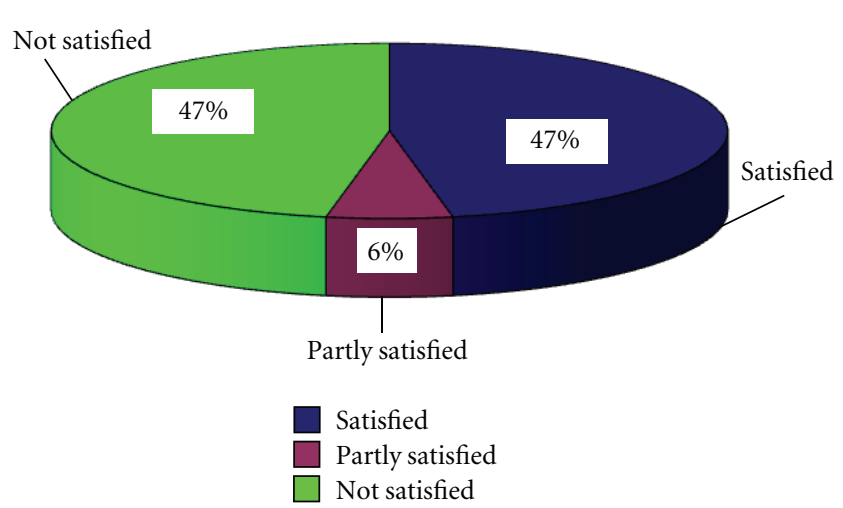

FiguRE 7: Level of satisfaction of biogas users in Kilimanjaro.

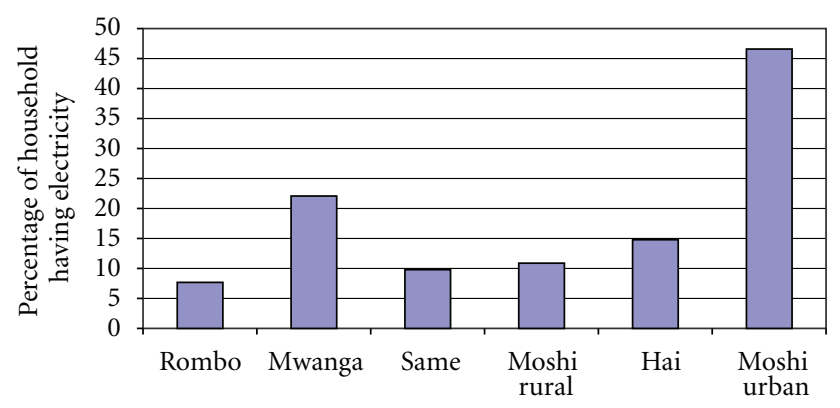

FIGURE 8: Percentage of household having electricity.

\section{Minimization of Deforestation Rates}

Figure 9 presents the graph that shows the amount of hectares of the forest that can be saved if the people can extend the application of biogas in the region. In this graph one unit presents the digester of the capacity of producing about four cubic meters of biogas per day. If each district can build about ten biogas plant per year, after one year about sixty biogas plants can be built and about 2,220 hectares can be saved per year. In each district about 370 hectares can be saved per year.

\section{Simulation Performance Results of the Hot Air Engines}

8.1. The Predicted Effects of Geometry on Ideal Engine Performance. Figures 10 and 11 present the variations of the geometrical parameters which are responsible for the variation of the swept volume of the engine. The swept volume is responsible for the power output of the engine. Its relationship with the dead volume via gas circuit parameters results in the efficiency of the engine. Figure 9 shows the variation of the diameter $(\mathrm{cm})$ of the bore of the expansion and compression piston of the engine. As the bore diameter increases, the power and efficiency of the engine increase

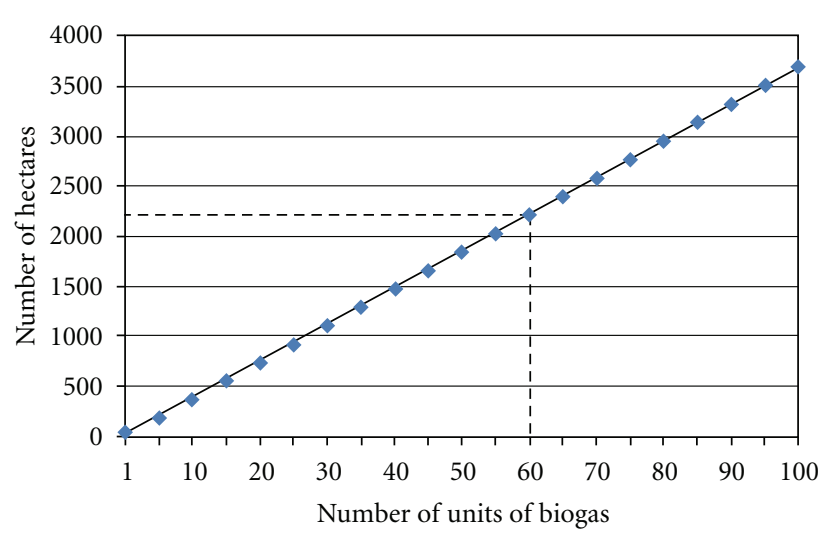

Figure 9: Reduction of deforestation rates.

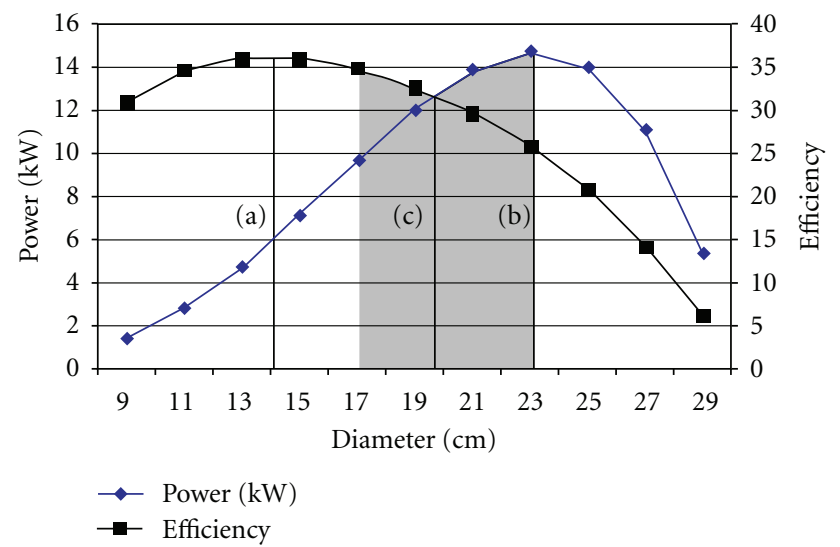

Figure 10: Power and efficiency at different values of Bore diameters.

reach maximum values and then decrease. The two maxima were not occurring at the same value of the diameter of the pistons. These variations were mainly attributed to the interrelation of geometrical and operational parameters.

Below line (a) both power and efficiency were increasing, but the efficiency reached its maximum value early due to its interdependence on the gas circuit parameters performance and swept volume of the engine. Some of the gas circuit parameters were the effectiveness of the regenerator, via its geometry and angle between successive wire screen of the regenerator (orientations), the NTU of the heater and cooler, via their geometric and material used, working gas, via its thermal properties, and so forth. Consider $10 \mathrm{~kW}$ power for medium economic activities. The shaded area was appropriate area for operation because the power and efficiency were reasonably higher.

Between lines (a) and (b) the power was still increasing, but efficiency was decreasing. The increase of power was attributed to the fact that the bore diameter plays an important role in the increasing of the swept volume responsible for power output. Ding et al. [21] pointed out that the stroke of piston has a significant influence on the heat transfer of expansion space and compression space; an optimized stroke of piston and corresponding swept volume and dead volume 


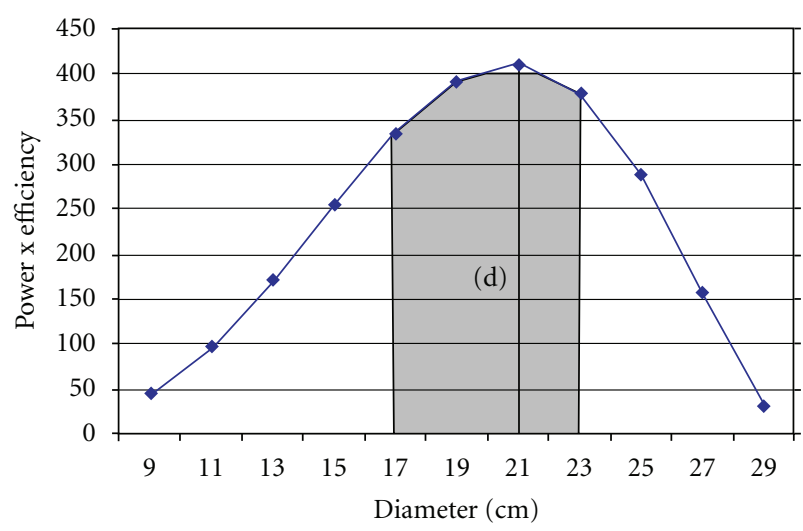

FIGURE 11: Diameters for useful work done by the engine.

are needed. The relationship between the swept volume and dead volume is critical in the engine performance. The swept volume of the engine depends on the volume of the expansion space via volume phase angle, where distribution of dimensionless dead space, shares identical distribution of dimensionless mass and the dimensionless mass rate with location and crack angle. The two graphs were crossing at point of line (c), the point close to the useful work done by the engine.

The useful work done by the engine was determined by the product of power and efficiency that was shown in Figure 11. The figure shows the optimum bore diameters for the compression and expansion spaces of the engine when useful work of an engine can get done in an instant in time. The line $(d)$ shows that the maximum value of the prediction that the useful work of the engine can get done in an instant in time was when the power output was about $13 \mathrm{~kW}$ and efficiency was about $29 \%$ when the diameter of the stroke was about $21 \mathrm{~cm}$. Below this point the power was increasing but the efficiency had reached its maximum value and it was decreasing. Shaded region below line (d) was appropriate area of operation because both power and efficiency are higher. At this point, the power was still increasing while the efficiency was decreasing, resulting from the interrelationship between the swept volume parameters and dead volume of the gas circuit of the heat exchangers. Supplying about $10 \mathrm{kWh}$ to each household for economic activities requires about 3.0 MWh to the whole Kilimanjaro region. This energy can be obtained from about $0.1 \%$ of the total agro-waste in the region.

\section{Conclusion and Recommendation}

In this study it was recognized that the biogas utilization is at low level in the Kilimanjaro region. It was also realized that biogas generated from livestock manual and night soil was not enough for cooking in the region. However, biogas from the agro-waste materials is sufficient for cooking and for small economic development in the region. About all of the respondents from Kilimanjaro region who use biogas energy as their source of energy for cooking and lighting wanted to extend biogas utility to electricity. About $98 \%$ of their neighbors wanted to have biogas as their source of energy. The materials for biogas production are available, and the condition for production is conducive. Therefore, utilisation of biogas as a source of energy to the Kilimanjaro population could contribute towards environmental conservation and economic empowerment. While the protection of the environment will be achieved through minimization of the use of firewood as a source of energy by the rural households, the economic empowerment (poverty reduction) is to be achieved as a result of the promotion of micro, small and medium enterprises (MSME) activities in rural areas through the availability of electricity to power various processing machines. Also there is a need to increase biogas production and to extend its use to electricity. Extending the utility of biogas to electricity will extend the utility of electrical appliances and encourage the installation of new processing machines. The processing machine will help in adding values to their products.

We have observed that 155 ha of land under annual crop production can produce biogas required for cooking in the region. The biogas required for cooking in the region per day is about 0.72 million cubic metres. The total energy required for each household in the region to have about $10 \mathrm{kWh}$ for economic development is about 3.0 MWh. From the potential of agro-waste materials from the land under annual crop production, it is possible to produce up to 0.55 billion $\mathrm{m}^{3}$ of biogas per day. This energy is by far sufficient for cooking and for economic activity in the region.

In Kilimanjaro region biogas technology has established itself as a technology with great potential which could exercise major influence in the energy prospect. Traditionally biogas technology was looked at as a source of energy for the rural population mainly for cooking and lighting, though it possessed several other benefits. It is recommendable to look at the biogas technology in an integrated manner to reap the multiple benefits, which this technology offers. However, one of its limitations is the low level of awareness of this technology in the entire region, followed by defects in construction and microbiological failure. This is why about $53 \%$ of the respondents in Kilimanjaro are partially or not satisfied with the technology, and they use firewood/charcoal to supplement biogas. There is a need to employ new method of generating biogas using local available materials and cheap method than the current procedure. Also it is recommendable to make use of batch type with right inoculum. Furthermore, designs to suit the microbial catalysts have been discussed for long but have yet to be realized. This indicates that the technology transfer is not complete and that it requires coordinated efforts.

\section{References}

[1] L. L. N. Mkiramweni and I. B. Mshoro, "Estimating the potential for Biogas production and application in Morogoro region, Tanzania," Energy \& Environment, vol. 20, no. 8, 21, no. 1, pp. 1357-1368, 2010.

[2] M. Saleh, “Tanzania electricity supply industry trends," E.S.I. Africa 2, 2002. 
[3] National Sample Census of agriculture 2002/2003, "Small holder agriculture volume III livestock sector-national report," 2006.

[4] United Republic of Tanzania, Ministry of Planning, Economy and Empowerment, views of the people 2007: (2008) Tanzanians given opinions on growth and reduction of income poverty, their quality of life and social well-being, and governance and accountability, REPOA, Dar es Salaam.

[5] S. Banerjee, "The enemy within," Down to Earth, vol. 5, no. 4, pp. 27-32, 1996.

[6] S. Lewanhak, The Revaluation of Women's Work, Earthscan, London, UK, 1989.

[7] M. K. Hazole and I. A. Harper, "Evaluation of deforestation rate in Morogoro region, Tanzania," in Proceeding of the 2nd Conference on Combating Desertification and Environmental Degradation in Africa, pp. 76-88, Khartoum, Sudan, April 2007.

[8] A. Dejene, E. K. Shishira, P. Z. Yanda, and F. H. Johnsen, "Land degradation in Tanzania: perception from the village," World Bank Technical Paper 370, 1997.

[9] F. P. Lekule, S. V. Sarwatt, E. Mollel, and A. H. Mgumia, "Centre of excellence on Biogas technology (CEBITEC)," Biogas Bulletin, 2003.

[10] K. von Mitzlaff, Engines for Biogas: Theory, Modification, Economic Operation, Deutsches Zentrum fur Entwicklungstechnologien-GATE, 1988.

[11] U. Werner, U. Stohr, and N. Hees, Biogas Plants in Animal Husbandry: A Practical Guide, Deutsches Zentrum fur Entwicklungstechnologien-GATE, 1989.

[12] R. Andersson, "Diesel or Gas motorengine for Biogas?” 2009, http://www.pcarrd.dost.gov.ph/message/viewtopic.php?id= 4378.

[13] C. D. Rakopoulos and C. N. Michos, "Generation of combustion irreversibilities in a spark ignition engine under Biogashydrogen mixtures fueling," International Journal of Hydrogen Energy, vol. 34, no. 10, pp. 4422-4437, 2009.

[14] S. K. Yoel, "Community and institution Biogas installation in Tanzania," in Proceedings of the 2nd Conference on Combating Desertification and Environmental Degradation in Africa, pp. 164-171, Khartoum, Sudan, April 2007.

[15] L. Cortsen, M. Lassen, and H. K. Nielsen, "Evaluation of small scale Biogas digesters in Turiani, Nronga, and Amani, Tanzania," in Proceedings of a Workshop Tune Landboskole, pp. 25-29, Denmark, 1996.

[16] F. Wu, L. Chen, C. Wu, F. Sun, and Y. Zhu, "Performance and optimum criteria for forward and reverse quantum stirling cycles," Energy Conversion and Management, vol. 39, no. 8, pp. 733-739, 1998.

[17] United Republic of Tanzania, National Bureau of Statistics, National Sample Census of Agriculture 2002/2003: Small Holder Agriculture, NBS, Dar es Salaam, 2006.

[18] W. J. van Nes, "Technical Biogas potential per district in Nepal. Gobar Gas Company, Nepal," 1992.

[19] National Sample Census of agriculture 2002/2003, "Small holder agriculture volume II livestock sector-national report," 2006.

[20] F. P. Lekule, S. V. Sarwatt, E. Mollel, and A. H. Mgumia, "Technological intervention for promoting smallholder integrated farming: a case study of Turiani, Morogoro, Tanzania," CEBITEC Biogas bulletin, estimating the potential for Biogas production and 1367 application in Morogoro Region, Tanzania, 2001.

[21] G. Ding, S. Huang, C. Zhang, X. Hu, X. Zhang, and F. Guo, "A study on design parameters of stirling engines for buildings," in Renewable Energy Resources and a Greener Future, vol. 4-5-8, Shenzhen, China, 2006. 

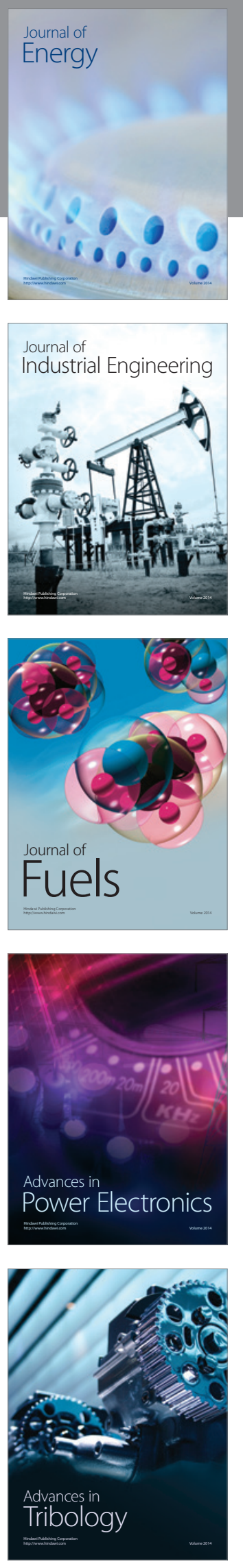
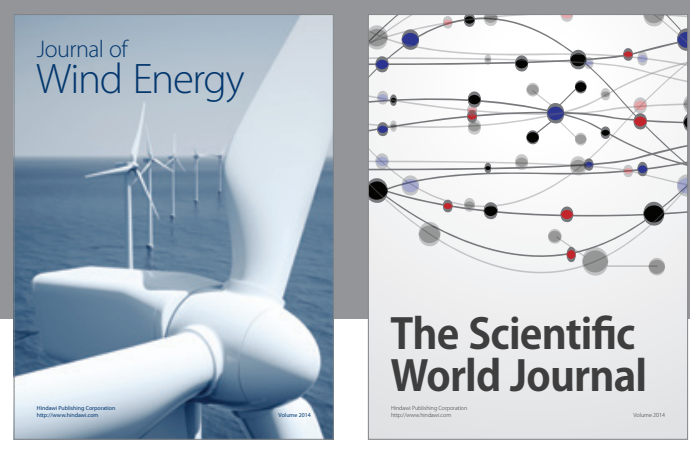

The Scientific World Journal

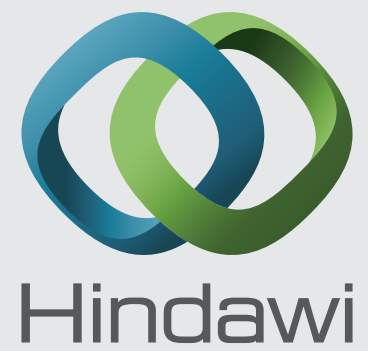

Submit your manuscripts at http://www.hindawi.com
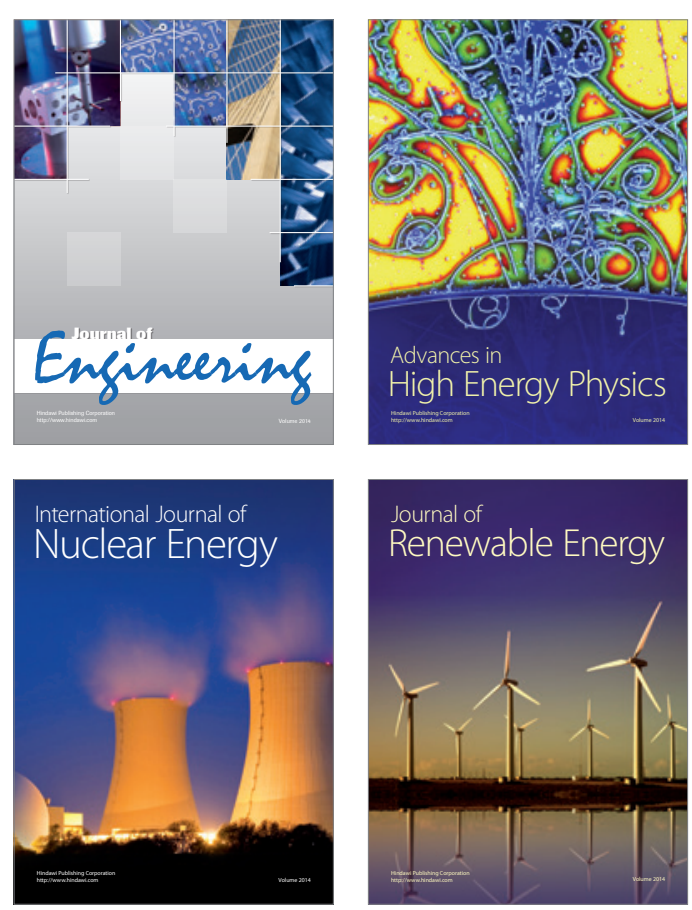

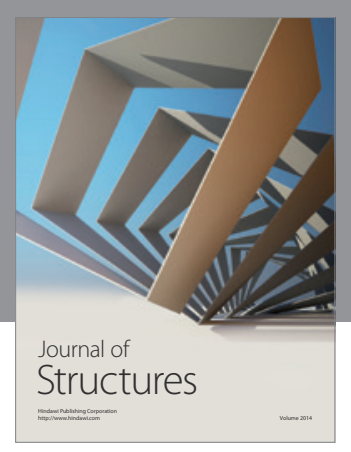

Rotating
Mechinery
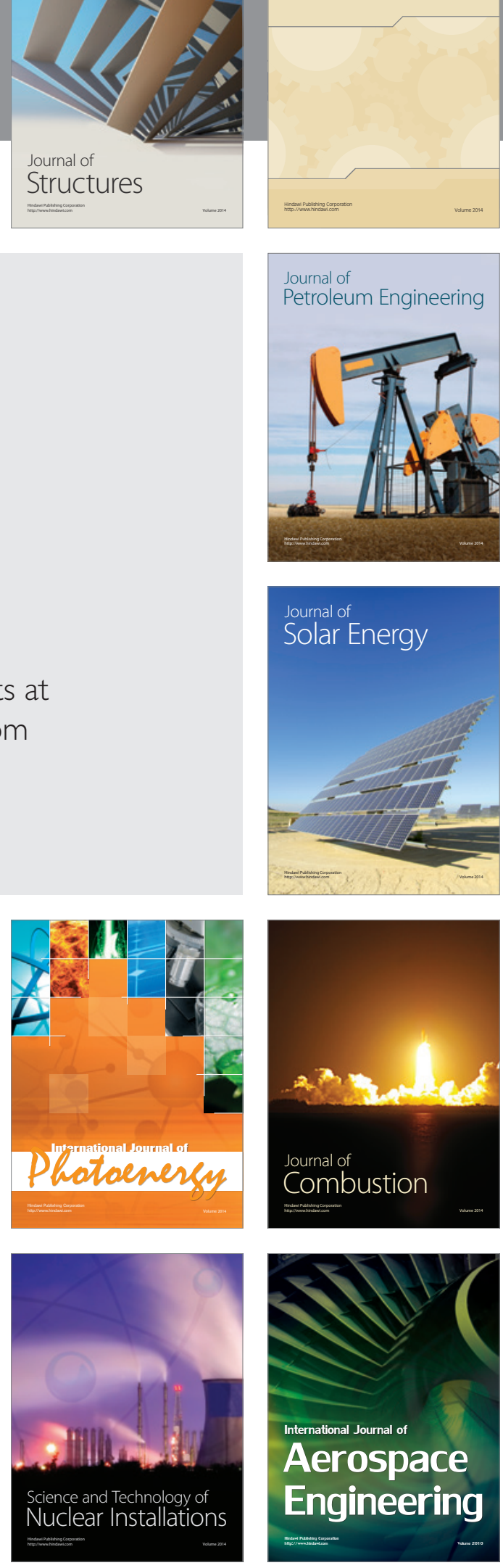